\title{
REFLECTION
}

\section{Rewarding Healthy Behaviors-Pay Patients for Performance}

Joanne $W u, M D, M P H$

Northwest Primary Care, Portland, Oregon

\begin{abstract}
Despite a considerable investment of resources into pay for performance, preliminary studies have found that it may not be significantly more effective in improving health outcome measures when compared with voluntary quality improvement programs. Because patient behaviors ultimately affect health outcomes, I would propose a novel pay-for-performance program that rewards patients directly for achieving evidence-based health goals. These rewards would be in the form of discounts towards co-payments for doctor's visits, procedures, and medications, thereby potentially reducing cost and compliance issues. A pilot study recruiting patients with diabetes or hypertension, diseases with clear and objective outcome measures, would be useful to examine true costs, savings, and health outcomes of such a reward program. Offering incentives to patients for reaching health goals has the potential to foster a stronger partnership between doctors and patients and improve health outcomes.
\end{abstract}

Ann Fam Med 2012;10:261-263. doi:10.1370/afm.1334

\section{INTRODUCTION}

$\mathrm{n}$ an effort to improve health care quality, insurance companies and

Medicare initiated pay-for-performance ( $\mathrm{P} 4 \mathrm{P})$ programs that reward

health care clinicians for achieving certain evidence-based performance measures. In theory, it seems as though this system should help improve patient health. Yet, a recent study of 500,000 patients in the United Kingdom found that $\mathrm{P} 4 \mathrm{P}$ did not result in better hypertension outcomes over a 7-year period, despite input of $\$ 2.8$ billion from the government. ${ }^{1}$ In the United States, studies have also shown mostly negative results, and concerns have arisen concerning deselection of complicated or low-income patients. ${ }^{2-5}$

Why might P4P fail? There are many potential factors, but one major cause is the complexity of effecting behavior change. P4P tries to improve health care based on the assumption that a single physician can successfully change the health-related behaviors of 1,000 patients. Indeed, physician counseling can help prime a patient for change, ${ }^{6}$ but ultimately it is the patient's behavior change that will directly affect health outcomes. A program that rewards patients financially for reaching measurable health goals has the potential to reduce issues of cost and compliance, 2 important obstacles to quality care. I therefore propose a new system: pay patients for performance (PP4P).

\section{WHAT PP4P WOULD LOOK LIKE}

Under PP4P, patients who meet evidence-based health care goals, such as keeping their blood pressure less than $140 / 90 \mathrm{~mm} \mathrm{Hg}$, or glycated hemoglobin $\left(\mathrm{A}_{1 \mathrm{c}}\right)$ at less than $7 \%$, will receive financial incentives that would 
be in the form of health care credits, which can be used toward discounts on medications, health insurance, procedures, and co-payments. The credits can be added onto the patients' health cards at their doctor's visits. When patients achieve preventive health goals, such as getting cancer-screening examinations at recommended intervals, they also earn credits. When they exercise, they can wear a heart rate monitor and bring the recordings to their employer to add credits to their health card, so employers can share administrative costs of updating the cards. By rewarding preventive care and healthy behaviors, this system will also benefit patients who have no chronic health issues; they can build up health credits for potential future use. Those who have no health insurance can also participate and build up discounts on medications and doctor's visits. Because co-payment discounts could be applied at any doctor's office participating in the PP4P plan, the office should not violate antikickback laws governing Medicaid and Medicare. ${ }^{7}$ Offering lower costs may further help perpetuate the cycle of compliance.

Importantly, in the past, insurance and employer programs that provided cash payments or matched participant contributions for quitting smoking and losing weight have produced mixed results. There is a general trend of improved behavior while the participants are actively receiving the rewards, but behaviors tended to regress once the rewards were no longer offered ${ }^{8-14}$ Presumably, to produce long-term behavior change, the financial rewards need to be ongoing. Giving rewards in the form of health credits, which reduce costs of future health services or medications, rather than cash payments, may allow for a more sustainable program.

Incentives that invest in further health improvement, such as reimbursements for gym memberships offered by insurance companies and employers, have the potential to decrease health care costs in the longterm. For example, Amway offered a low-cost gym membership and wellness program to its employees in 2007. An analysis of that program in 2010 found that active participants decreased their medical and prescription claims by $8 \%$ compared with a $2 \%$ increase in nonparticipants. ${ }^{15}$

\section{FINANCING PP4P}

The million dollar question is, who would pay for this reward system? Insurance plans, employers, pharmaceutical companies, and the government all stand to benefit financially in the long-term from patients' healthy behaviors and adherence to medication, so they should all contribute. There are already increas- ing numbers of insurance plans paying physicians for performance, so some of that payment could be shifted toward decreasing costs for patients. PP4P encourages medication compliance, so pharmaceutical companies can use that increased income toward rewarding patients with medication discounts. Government funding can help offset administrative costs of creating a system to monitor health credits.

Examining the funds spent on P4P just from insurance plans can give an estimate of what amount might be available to spend on each patient under a PP4P program. In 2003, a health plan offered a physician group with 10,000 patients a potential bonus of $\$ 270,000$ for that year. ${ }^{2}$ It can be assumed that bonus amounts since then have increased to account for inflation, so that allows for more than $\$ 27$ per patient. This amount may not seem substantial, but for some patients, even a $\$ 10$ medication or co-payment for a doctor's visit represents a considerable deterrent. Using the $\$ 30$ available for that patient, one could reduce co-payments for doctor's visits every 2 months from $\$ 10$ to $\$ 5$, which could boost compliance with follow-up visits. Because not every patient will meet goals, the potential reward amount for a successful patient will be even higher. With the added cost savings that can be offered by pharmaceutical companies for medications and potential contributions from employers and the government, rewards can become even more significant.

\section{ACCEPTABILITY OF PP4P}

It will be important to study patient acceptance of incentive programs, particularly because discounts for medications and doctor's visits may have a disproportionate effect on patients living in poverty and those utilizing Medicaid and Medicare. Studies have found divided opinions regarding financial rewards for changing behaviors, such as quitting smoking, losing weight, controlling blood pressure or blood glucose. ${ }^{16,17}$ Among participants in one study, smokers were significantly more likely to think that it is a good idea to pay smokers to quit smoking, and obese participants were more likely to think it is a good idea to pay people to lose weight. ${ }^{16}$ Another study showed that rewards for behavior changes are generally more acceptable than are penalties for not meeting health goals. Also, participants were more willing to support funding for interventions when they deemed members of the target group to be less responsible for their condition. ${ }^{17}$

Both these studies examined attitudes regarding direct monetary rewards rather than incentives in the form of discounts on further health services or medications, which is what PP4P would offer. People may find 
PP4P's health credit incentives more acceptable. Also, people tended to be more approving of an incentive program when they were likely to benefit from it themselves, and PP4P has the potential to reward a broad range of patients, even those who are generally healthy.

It will be crucial to communicate to patients how enrollment in the PP4P program works and fully explain the added benefits of the program. In 2006, West Virginia reformed its Medicaid program, providing reduced basic benefits to most healthy children and adults, but allowing them to opt in for enhanced benefits by signing a form in which they agreed to try to stay healthy and comply with regular check-ups, treatment plans, and preventive screenings. ${ }^{18}$ Unfortunately, initial reports looking at the effects of the program show that it has suffered from poor enrollment because patients do not understand what it offers, whether it costs more money, and how to opt in for the program. ${ }^{19}$ Learning from that experience, it is clear that any new patient incentive program will need to be explained carefully to potential participants, and it may have more success with automatic enrollment with a choice to opt out rather than having to opt in.

\section{NEXT STEPS}

A pilot project implementing PP4P in a small community would be useful to expose potential flaws and show true costs and savings. It would be practical first to recruit patients with hypertension and diabetes to participate. There are clear and objective evidencebased quality measures for those diseases, such as blood pressure and hemoglobin $\mathrm{A}_{1 \mathrm{c}}$ goals. It would be interesting to see how a reward, such as lower medication costs, may motivate patients to take the initiative in improving diet and exercise, scheduling more frequent appointments, and asking physicians to increase medication doses.

The medical system as it currently operates places all the responsibility and rewards of quality of care on physicians. This system perpetuates a paternalistic approach that is not cost efficient or sustainable. Highquality health care requires a team approach. Patients deserve a greater role in improving their wellness and reaping the rewards from it.

To read or post commentaries in response to this article, see it online at http://www.annfammed.org/content/10/3/261.

Key words: pay for performance; quality improvement; health outcome measures; incentive, reimbursement; outcome; healthcare reform

\section{References}

1. Serumaga B, Ross-Degnan D, Avery AJ, et al. Effect of pay for performance on the management and outcomes of hypertension in the United Kingdom: interrupted time series study. BMJ. 2011;342:d108.

2. Rosenthal MB, Frank RG, Li Z, Epstein AM. Early experience with pay-for-performance: from concept to practice. JAMA. 2005;294 (14):1788-1793.

3. Glickman SW, Ou FS, DeLong ER, et al. Pay for performance, quality of care, and outcomes in acute myocardial infarction. JAMA. 2007:297(21):2373-2380.

4. McDonald R, Roland M. Pay for performance in primary care in England and California: comparison of unintended consequences. Ann Fam Med. 2009;7(2):121-127.

5. Chen JY, Tian H, Juarez DT, et al. Does pay for performance improve cardiovascular care in a "real-world" setting? Am J Med Qual. 2011;26(5)340-348.

6. Kreuter MW, Chheda SG, Bull FC. How does physician advice influence patient behavior? Evidence for a priming effect. Arch Fam Med. 2000;9(5):426-433.

7. Minnesota Medical Association. Waiving copays and reducing fees. http://www.mnmed.org/Portals/mma/PDFs/Waiving\%20Copays\%20 and\%20Reducing\%20Fees\%20final.pdf.

8. Cahill K, Perera R. Competitions and incentives for smoking cessation. Cochrane Database Syst Rev. 2011;(4):CD004307.

9. John LK, Loewenstein G, Troxel AB, Norton L, Fassbender JE, Volpp KG. Financial incentives for extended weight loss: a randomized, controlled trial. J Gen Intern Med. 2011;26(6):621-626.

10. Morgan PJ, Collins CE, Plotnikoff RC, et al. Efficacy of a workplacebased weight loss program for overweight male shift workers: the Workplace POWER (Preventing Obesity Without Eating like a Rabbit) randomized controlled trial. Prev Med. 2011;52(5):317-325.

11. Volpp KG. Paying people to lose weight and stop smoking. LDI Issue Brief. 2009;14(3):1-4.

12. Finkelstein EA, Linnan LA, Tate DF, Birken BE. A pilot study testing the effect of different levels of financial incentives on weight loss among overweight employees. J Occup Environ Med. 2007;49(9): 981-989.

13. Volpp KG, John LK, Troxel AB, Norton L, Fassbender J, Loewenstein $G$. Financial incentive-based approaches for weight loss: a randomized trial. JAMA. 2008;300(22):2631-2637.

14. Volpp KG, Pauly MV, Loewenstein G, Bangsberg D. P4P4P: an agenda for research on pay-for-performance for patients. Health Aff (Millwood). 2009;28(1):206-214

15. Martinez $S$. Workplace wellness programs have double benefit: healthier employees, lower health care costs. Grand Rapids Press. February 27, 2011. http://www.mlive.com/business/west-michigan/ index.ssf/2011/02/workplace_wellness_programs_ha.html.

16. Long JA, Helweg-Larsen M, Volpp KG. Patient opinions regarding 'pay for performance for patients'. J Gen Intern Med. 2008;23(10): 1647-1652.

17. Promberger M, Brown RCH, Ashcroft RE, Marteau TM. Acceptability of financial incentives to improve health outcomes in UK and US samples. J Med Ethics. June 13, 2011 [epub ahead of print].

18. Steinbrook R. Imposing personal responsibility for health. $N$ Engl J Med. 2006;355(8):753-756.

19. Trapp D. When incentives lack appeal: Medicaid reform meets confusion, skepticism. Am Med News. November 3, 2008. http://www .ama-assn.org/amednews/2008/11/03/gvsa1103.htm. 